\title{
Cinnamyl alcohol oxidation using supported bimetallic Au-Pd nanoparticles: an investigation of autoxidation and catalysis
}

\author{
Emilia Rucinska, Peter J. Miedziak, Samuel Pattisson, Gemma L. Brett, Sarwat Iqbal, David J. \\ Morgan, Meenakshisundaram Sankar and Graham, J. Hutchings.*
}

\author{
Cardiff Catalysis Institute, Cardiff University, Main Building, Park Place, Cardiff, CF10 3AT. \\ e-mail: hutch@cf,.ac.uk
}

\begin{abstract}
In this study we examine the autoxidation and its role on the catalytic aerobic oxidation of cinnamyl alcohol using supported AuPd nanoparticles. We further report the crucial role of reaction conditions on the reaction pathway. Close attention is paid to the mechanism of benzaldehyde formation, a byproduct formed in large quantities from the process of autoxidation. The activity of the catalysts depends on the preparation method with different sizes of nanoparticles obtained by the two methods of preparation. The catalysts can inhibit the autoxidation process or these two processes, namely catalytic oxidation and autoxidation can coexist. In the case of oxidation of cinnamyl alcohol, 0.5 $\%(w t) A u ~ 0.5 \%(w t) P d / \mathrm{TiO}_{2}$ catalysts prepared by various methods allow different products distribution to be obtained. The catalyst prepared by sol-immobilisation method seems to prevent the autoxidation leaving the catalytic process dominant. Catalysts prepared by impregnation method seems to enable both the catalytic process and auto-oxidation occur at the same time. We show that using the optimum catalyst for this reaction the autoxidation process can be mitigated.
\end{abstract}




\section{Introduction}

In recent years, considerable research has been directed on producing bulk and specialty chemicals from renewable and sustainable feedstock like lignocellulosic biomass. These processes must be environmentally benign, in line with the principles of green chemistry and be economically sustainable. Numerous reports have shown that development of new heterogeneous catalysts underpin the efforts in achieving this objective. ${ }^{1}$ It has been reported that supported gold nanoparticles are active for the catalytic hydrochlorination of acetylene to vinyl chloride and for the low-temperature oxidation of $\mathrm{CO}^{2}$ Subsequent research on this area has shown that the addition of gold to another metal, in a bimetallic nanoparticle, significantly increases the catalytic properties, such as activity, selectivity and stability. ${ }^{3}$ For example, supported AuPd catalysts have been reported to be several times more active compared to their monometallic counterparts (monometallic $\mathrm{Au} \&$ monometallic $\mathrm{Pd}$ ) for the selective oxidation of alcohols, polyols and hydrocarbons using $\mathrm{O}_{2}$ as the oxidant. This aerobic oxidation route is a more environmentally benign alternative to oxidation processes involving stoichiometric oxidants such as chromates and permanganates. ${ }^{4,1,5,6}$

Selective aerobic oxidation of cinnamyl alcohol has received considerable attention recently in the pursuit to produce bulk and speciality chemicals from renewable feedstocks. Cinnamyl alcohol is an example of an allylic alcohol and is one of the main components of lignin. The presence of both alkene and primary alcohol functionality presents a challenge for chemoselective oxidation. Furthermore, the reaction network is complex, resulting in the formation of a number of by-products. Hence controlling the selectivity of this reaction is important and it has been reported that the nature of catalyst and reaction conditions play crucial role in controlling the selectivity of this reaction. Cinnamaldehyde, obtained by the selective oxidation of the primary alcohol group is the most desired product as it is used in the production of insecticides and as a common food/perfume additive. ${ }^{7-10}$ During the oxidation of cinnamyl alcohol, Corma et al. achieved an excellent yield to cinnamaldehyde (99 \%) using a $\mathrm{Au} / \mathrm{CeO}_{2}$ catalyst prepared by deposition-precipitation method. ${ }^{3}$ Prati et al. obtained high conversion of cinnamyl alcohol over $1 \% \mathrm{AuPd} / \mathrm{TiO}_{2}$ catalyst prepared by sol-immobilisation method, with products of cinnamaldehyde and 3-phenyl-1-propanol at $60{ }^{\circ} \mathrm{C}$ under oxygen. Conversion and selectivity varied depending on Au-Pd metal ratio. The most active catalyst has been found to be 0.73 $\% \mathrm{Au}-0.27 \% \mathrm{Pd}$ (conversion was $72 \%$ after $2 \mathrm{~h}$, selectivity to cinnamaldehyde was $85 \%$ and selectivity to 3-phenyl-1-propanol was $13 \%) .{ }^{11}$ Baiker et al. oxidised cinnamyl alcohol with the use of $5 \% \mathrm{Pd} / \mathrm{Al}_{2} \mathrm{O}_{3}$ at $65{ }^{\circ} \mathrm{C}$ under air. Numerous products were obtained after reaction in a slurry reactor, mentioned here with selectivities in brackets: cinnamaldehyde (63\%), 3-phenyl-1-propanol (35\%), methylstyrene $(0.5 \%)$, propylbenzene $(0.2 \%)$, ethylbenzene $(0.8 \%)$, 3-phenylpropionaldehyde $(0.6$ 
$\%)$, styrene $(0.1 \%) .{ }^{12}$ However, the researchers did not report the phenomenon of autoxidation in the literature discussed above. ${ }^{3,11,12}$

Benzaldehyde has been reported as one of the by-products in several investigations. ${ }^{13-15}$ The autoxidation of cinnamyl alcohol has been reported but not extensively studied in relation to the effect of a catalyst. Niklasson et al. demonstrated that cinnamyl alcohol undergoes autoxidation. ${ }^{16}$ They reported that the autoxidation process is facile and is fairly fast when initiated, under several different reaction conditions. ${ }^{16}$ Costa et al. studied the oxidation of cinnamyl alcohol catalysed by $\mathrm{Au}-\mathrm{Ag}$ nanotubes (NT) and the phenomenon of autoxidation was also reported. This work reported large amounts of benzaldehyde which they suggested was formed from cinnamaldehyde by a radical pathway in the bulk phase, rather than on the catalyst surface. The reaction was carried out at $100{ }^{\circ} \mathrm{C}$ under 6 bar of oxygen in the presence and absence of a catalyst. The conversion for the blank reaction was $28 \%$ after $2.5 \mathrm{~h}$ with a selectivity to cinnamaldehyde of $44.5 \%$ and selectivity to benzaldehyde of $53 \%$. The reaction performed with an Au-Ag NT catalyst gave $99.1 \%$ conversion, with selectivity to cinnamaldehyde of $21.1 \%$ and selectivity to benzaldehyde a $73 \%$. The researchers suggested that the activation of a radical pathway occurred due to the presence of hydroperoxides (from the substrate) or because of activation of molecular oxygen by Au. ${ }^{15}$

Oxidation using an oxidant without any catalyst, termed as autoxidation, is a very common process in the selective oxidation of hydrocarbons such as cyclohexane ${ }^{17,18}, \mathrm{p}$-xylene ${ }^{19}, \alpha$-pinene ${ }^{20,21}$ and cumene, ${ }^{22}$ to produce bulk chemicals. Considerable efforts have been made to understand the mechanism of autoxidation processes. ${ }^{23-25}$ Conte $e t$ al. ${ }^{23}$ have written a literature review, in which they pointed to the need to develop heterogeneous catalysts that allow not only high conversion of a given substrate, but also high selectivity to the desired product in the process of catalytic oxidation. The authors clearly indicated that autoxidation taking place in almost every oxidation process affects the selectivity of the catalytic process, mainly due to the radical nature of the reaction. Thus there is the need to design catalysts that ensure high selectivity and can be used on an industrial scale. It is also necessary to determination the pathway of oxygen activation, this can be achieved by investigating the reaction mechanism to determine products that are formed by the radical pathway.

The pathway of oxygen activation depends on the oxidized substrate, the reaction conditions and the catalyst used. The review by Conte et al. shows the mechanisms of oxidation of various reactions, including: oxidations of hydrocarbons by metal oxides, oxidation of alkenes to aldehydes, selective alcohol oxidation by means of the bathophenanthroline complex in water and enzymatic reactions. In the case of each reaction, oxygen is activated as a result of different routes and autooxidation is very often an accompanying process, initiated by various factors, for example the presence of 
hydroperoxides, the character of the substrates or high temperature. The authors stressed that autoxidation is an important factor in oxidation reactions and cannot be neglected but carefully studied. $^{23}$

In this paper we investigate the autoxidation pathway in cinnamyl alcohol oxidation, with focus on the effect of catalyst, scavengers and test intermediate reactions. We propose that using catalysts prepared by the sol immobilisation method can prevent the autoxidation reaction taking place, resulting in a higher selectivity to the desired product cinnamaldehyde.

\section{Experimental}

\section{Catalyst preparation}

Catalysts have been prepared according to the procedures described in previous papers where oxidation of benzyl alcohol has been studied. ${ }^{1,26}$

\section{Impregnation method}

$\mathrm{PdCl}_{2}(0.0083 \mathrm{~g})$ (Alfa Aesar) was dissolved in an aqueous solution of $\mathrm{HAuCl}_{4} \cdot \mathrm{H}_{2} \mathrm{O}(0.4082 \mathrm{ml}$, concentration: $12.25 \mathrm{mg} / \mathrm{ml})(\mathrm{Strem}) . \mathrm{TiO}_{2}(0.99 \mathrm{~g})$ (Evonik, P25) was added to the solution with the addition of small amount of water. The slurry was heated at $90{ }^{\circ} \mathrm{C}$ until the consistency of toothpaste was obtained. The paste was dried overnight at $110{ }^{\circ} \mathrm{C}$ in an oven after which the solid was ground in a pestle and mortar, and calcined in static air at $400{ }^{\circ} \mathrm{C}$ for $3 \mathrm{~h}$.

\section{Sol-immobilisation method}

Aqueous solutions of $\mathrm{PdCl}_{2}\left(1.1494 \mathrm{ml}\right.$, concentration: $4.35 \mathrm{mg} / \mathrm{ml}$ ) (Alfa Aesar) and $\mathrm{HAuCl}_{4} \cdot \mathrm{H}_{2} \mathrm{O}$ (0.4082 $\mathrm{ml}$, concentration: $12.25 \mathrm{mg} / \mathrm{ml}$ ) (Strem) were added to deionized water under vigorous stirring, followed by PVA (1wt\% aqueous solution, Aldrich, MW= 10,000) $(\mathrm{PVA} /(\mathrm{Au}+\mathrm{Pd})(\mathrm{wt} / \mathrm{wt})$ $=1)$ and a freshly prepared solution of $\mathrm{NaBH}_{4}\left(0.1 \mathrm{M}, \mathrm{NaBH}_{4} /(\mathrm{Au}+\mathrm{Pd})(\mathrm{mol} / \mathrm{mol})=5\right)$. After an hour, the formed nanoparticles were immobilised onto a $\mathrm{TiO}_{2}$ support by addition of $\mathrm{TiO}_{2}$ and acidification of the solution to $\mathrm{pH}=1$ with sulphuric acid. The solid was filtered and washed with distilled water followed by drying overnight at $110{ }^{\circ} \mathrm{C}$ in an oven, the solid was ground in pestle and mortar.

\section{Catalyst testing}

The oxidation of cinnamyl alcohol was carried out in Radley reactor at $120{ }^{\circ} \mathrm{C}$ under an oxygen pressure of 3 bar. $5 \mathrm{ml} 0.5 \mathrm{M}$ cinnamyl alcohol in toluene was charged into the reactor, followed by $0.01 \mathrm{~g}$ of a catalyst. The glass reactor flasks were purged with oxygen 3 times before caps were sealed 
and placed on the hot plate. The stirring rate was set to $1000 \mathrm{rpm}$. The collected mixture of products was centrifuged to separate the catalyst. Samples were diluted with mesitylene as internal standard and analysed by gas chromatography (Agilent Technologies 7820 A) fitted with a CPwax 52 CB capillary column and a flame ionization detector. Conversion and selectivity values are reported within $\pm 3 \%$ error (calculated as a standard deviation).

Conversion of tested substrates was calculated with the use of following equation $(\mathrm{C}$ subA, $\mathrm{C}$ subBrepresent the substrate concentrations $\left[\mathrm{mol} / \mathrm{dm}^{3}\right]$ at the beginning of the reaction and at the end of the reaction, respectively):

$$
\text { Concentration }=\frac{C \operatorname{sub} A-C \operatorname{subB}}{C \text { subA }} \times 100 \%
$$

Selectivity was calculated according to following equation:

$$
\text { Selectivity }=\frac{C \text { compound }}{\sum \text { C products }} \times 100 \%
$$

The influence of water on the oxidation of cinnamyl alcohol has been tested by the addition of $2 \mathrm{ml}$ of water to the standard reaction mixture. Standard high stirring rate of $1000 \mathrm{rpm}$ was sufficient for this experiment in order to create an emulsion as two phases were present. The catalyst resided in the aqueous phase in the absence of stirring, however, the post reaction aqueous phase has been analysed and only traced amounts of cinnamyl alcohol and cinnamaldehyde were detected.

\section{SEM}

Microscopy was performed on a Tescan Maia3 field emission gun scanning electron microscope (FEGSEM) operating at $15 \mathrm{KV}$. Images were acquired using the backscattered electron detector. Samples were dispersed as a powder onto 300 mesh copper grids coated with holey carbon film.

\section{XPS}

X-ray photoelectron spectroscopy (XPS) data was collected on a Thermo-Fisher Scientific K-Alpha+ $\mathrm{X}$-ray photoelectron spectrometer using a monochromatic $\mathrm{Al} \mathrm{K \alpha} \mathrm{X}$-ray source operating at $72 \mathrm{~W}$. Survey scans and high resolution scans were acquired at a pass energy of $150 \mathrm{eV}$ and $40 \mathrm{eV}$ respectively. Charge neutralization was achieved using a combination of low energy electrons and argon ions, resulting in a $\mathrm{C}(1 \mathrm{~s})$ binding energy of $284.8 \mathrm{eV}$; experimental binding energies are quoted $\pm 0.2 \mathrm{eV}$ 


\section{Results and discussion}

Due to the variety of possible products that can be formed during the oxidation of cinnamyl alcohol, it was important to establish the reaction pathways and product distributions for the experiments conducted under our reaction conditions. In general, the reaction network based on observed products, has been found to agree with the literature although it is not identical. The products obtained during our studies are shown in figure 1, the main products are: cinnamaldehyde (CinnALD), benzaldehyde (benzALD), 3-phenyl-1-propanol (PP), methylstyrene (MS), styrene, benzoic acid (BenzACID). CO, and $\mathrm{CO}_{2}$. Further unidentified organic substances were observed in trace amounts (typically $<5 \%$ ).

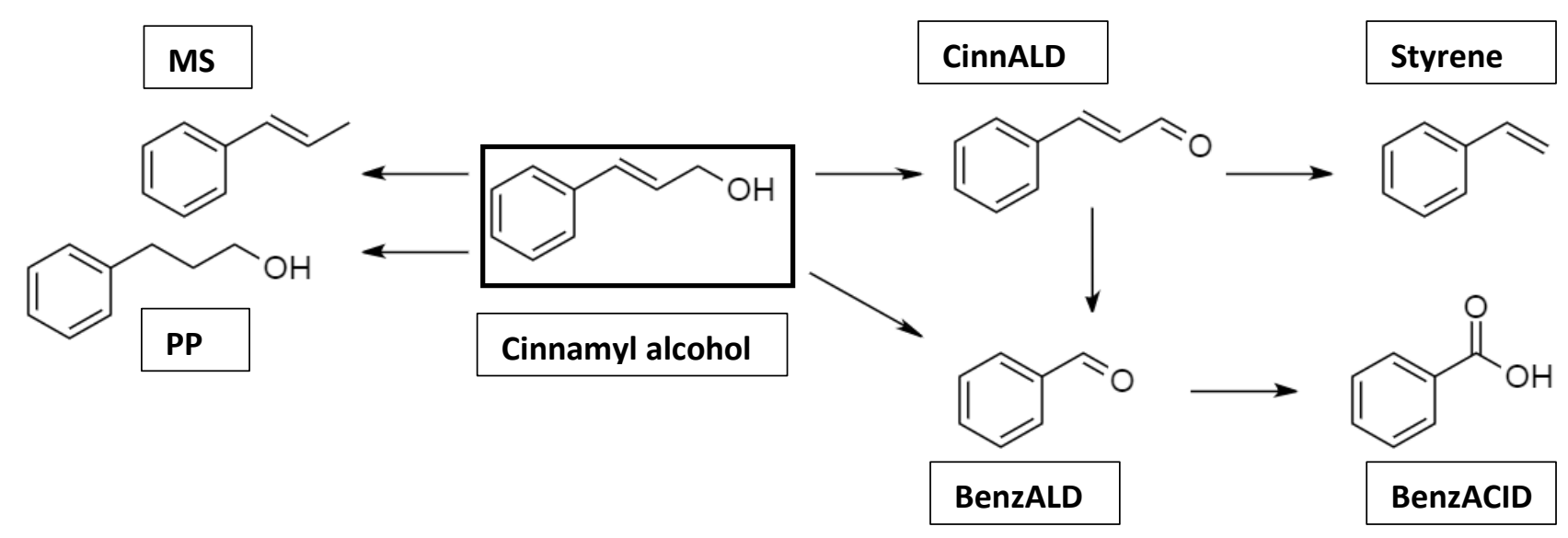

Figure 1 Products obtained during current investigation. 


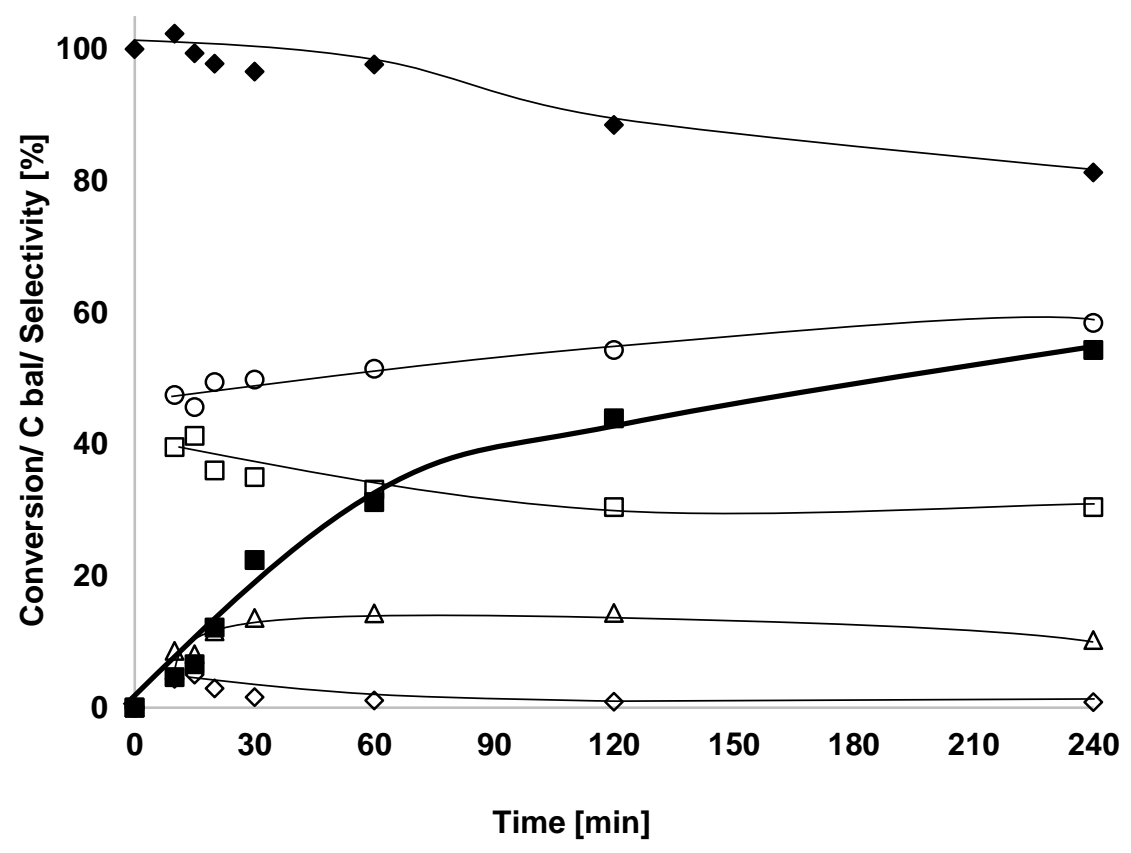

Figure 2 Time online profile for the autoxidation of cinnamyl alcohol. Reaction conditions: $\mathrm{O}_{2}: 3$ bar; temperature, $120{ }^{\circ} \mathrm{C}$; $0.5 \mathrm{M}$ cinnamyl alcohol in toluene. Conversion ( $\square$ ); Carbon balance ( $\left.\diamond\right) ;$ $\operatorname{CinnALD}(\square) ; \operatorname{BenzALD}(0) ; \operatorname{PP}(\diamond) ; \operatorname{BenzACID}(\Delta)$

When the oxidation reaction was carried out without any catalyst, significant conversion was observed with high selectivity to 3 major products: cinnamaldehyde, benzaldehyde and benzoic acid. The results from the time on line study of the autoxidation reaction is presented in Figure 2. After 4h, $60 \%$ cinnamyl alcohol conversion was achieved with a selectivity profile of $30 \%$ cinnamaldehyde, $60 \%$ benzaldehyde, $10 \%$ benzoic acid and $<1 \%$ of 3-phenyl-1-propanol. To contrast this activity with catalytic activity, $1 \% \mathrm{AuPd} / \mathrm{TiO}_{2}(\mathrm{Imp})$ catalyst was used for the selective oxidation of cinnamyl 
alcohol under identical reaction conditions. The time on line profile for the catalytic reaction is presented in Figure 3.

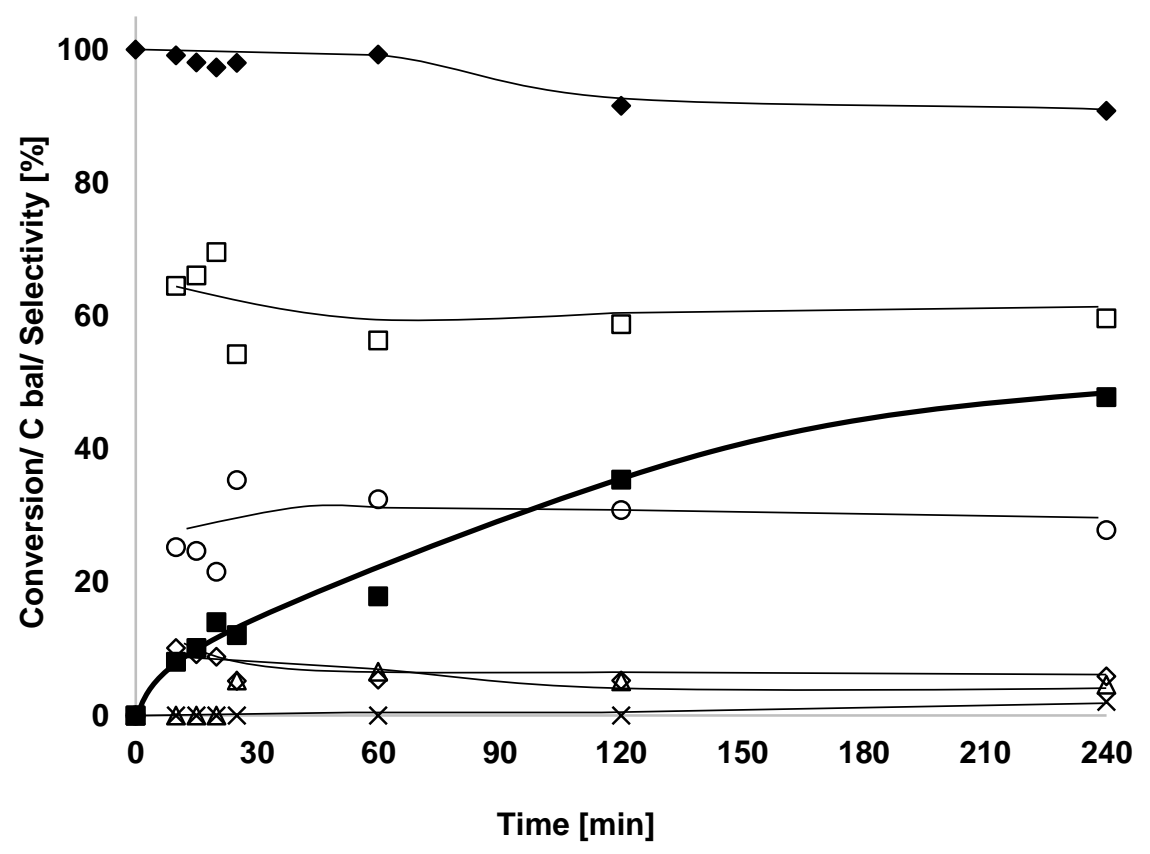

Figure 3 Time on line profile for the catalytic oxidation of cinnamyl alcohol using $0.50 \% A u 0.50$ $\% \mathrm{Pd}_{\mathrm{TiO}} \mathrm{T}_{2}$ (Imp). Reaction conditions: $1 \% \mathrm{AuPd} / \mathrm{TiO}{ }_{2}$ (Imp), $10 \mathrm{mg}$; oxygen pressure, 3 bar; temperature, $120{ }^{\circ} \mathrm{C}$; $0.5 \mathrm{M}$ cinnamyl alcohol in toluene. Conversion ( $\square$ ); Carbon balance ( $\left.\checkmark\right)$; CinnALD ( $\square) ; \operatorname{BenzALD}(O) ; \operatorname{PP}(\diamond) ; \operatorname{BenzACID}(\Delta) ; \operatorname{MS}(X)$

The comparison of Figures 2 and 3 shows that the reaction with the use of a $1 \% \mathrm{AuPd} / \mathrm{TiO}_{2}(\operatorname{Imp})$ had a lower conversion than the blank reaction, especially during the first $2 \mathrm{~h}$. However, higher selectivity to cinnamaldehyde $(60 \%)$ was observed. It is notable that the formation of benzoic acid decreased and the selectivity to benzaldehyde was lower (30\%). Selectivity to the products that are formed as a result of hydrogen transfer processes (methylstyrene and 3-phenyl-1-propanol) was below $5 \%$.

Figure 4 shows the results of the catalytic oxidation of cinnamyl alcohol using $1 \% \mathrm{AuPd} / \mathrm{TiO}_{2}(\mathrm{SIm})$ catalyst. This SIm catalyst displayed high conversion (85\%) with high selectivity to cinnamaldehyde $(80 \%)$. Furthermore, in this reaction only small amounts of benzaldehyde (selectivity around $3 \%$ ) and no benzoic acid was detected, which is significantly lower than both autocatalytic oxidation and catalytic oxidation using $1 \% \mathrm{AuPd} / \mathrm{TiO}_{2}$ (Imp). Also, comparison of carbon balances suggests that SIm catalyst due to its high selectivity prevents formation of hard to identify products (small amounts compounds formed as the effect of further radical processes), as in the case of Imp catalyst and blank reaction. The selectivity of 3-phenyl-1-propanol was slightly higher (10\%) and that of methylstyrene, 
formed by the hydrogenolysis of cinnamyl alcohol, was relatively low (3\%). Despite the autocatalytic reaction being active under our reaction conditions, the results from catalytic reactions, specifically using $1 \% \mathrm{AuPd} / \mathrm{TiO}_{2}(\mathrm{SIm})$ catalyst, clearly shows that the autocatalytic pathway and the catalytic pathways are significantly different. It is well established that autocatalytic pathways, especially in oxidation, are typically radical pathways. ${ }^{15,23,27}$

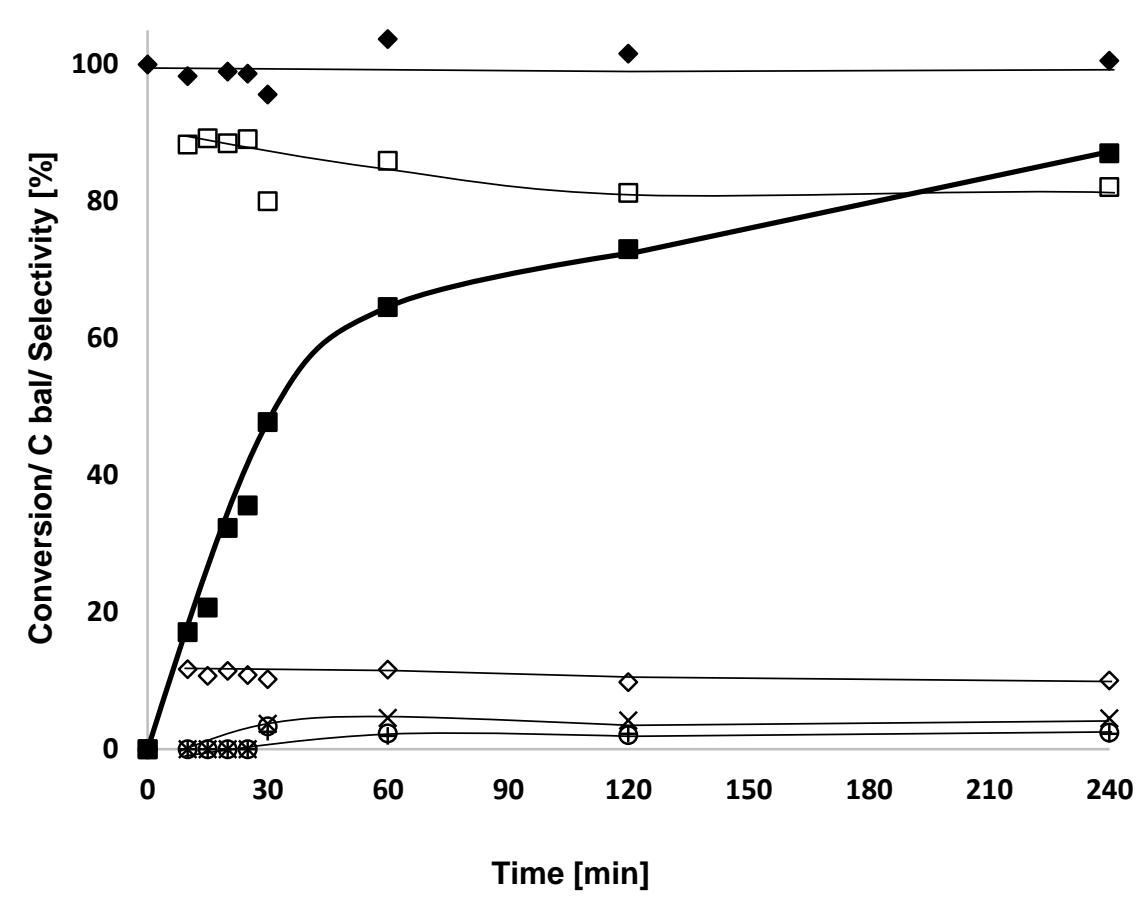

Figure 4 Catalytic oxidation of cinnamyl alcohol using $0.50 \% A u \quad 0.50 \% \mathrm{Pd} / \mathrm{TiO}_{2} / \mathrm{TiO}_{2}(\mathrm{SIm})$. Reaction conditions: $1 \% \mathrm{AuPd} / \mathrm{TiO}_{2}(\mathrm{Sim}), 10 \mathrm{mg}$; oxygen pressure, $3 \mathrm{bar}$; temperature, $120{ }^{\circ} \mathrm{C} ; 0.5$ $\mathrm{M}$ cinnamyl alcohol in toluene. Conversion ( $\square)$; Carbon balance $(\diamond)$; CinnALD $(\square)$; BenzALD $(\mathrm{O})$; PP $(\diamond)$; MS $(\times)$; Styrene $(\mathbf{I})$

To confirm the radical mechanism, the oxidation of cinnamyl alcohol was carried out with the addition of scavengers, in the absence of catalyst. Two types of scavengers were tested: hydroquinone and diphenylamine. Diphenylamine ${ }^{28}$ is a scavenger for carbon centred radicals and hydroquinone ${ }^{29,30}$ is a scavenger for oxygen centred radicals. As is shown in Figure 5, the scavengers significantly decreased the conversion of cinnamyl alcohol, indicating that radicals play an important role in the autoxidation of cinnamyl alcohol, which is in good agreement with the results of experiments reported by Costa. ${ }^{15}$ 


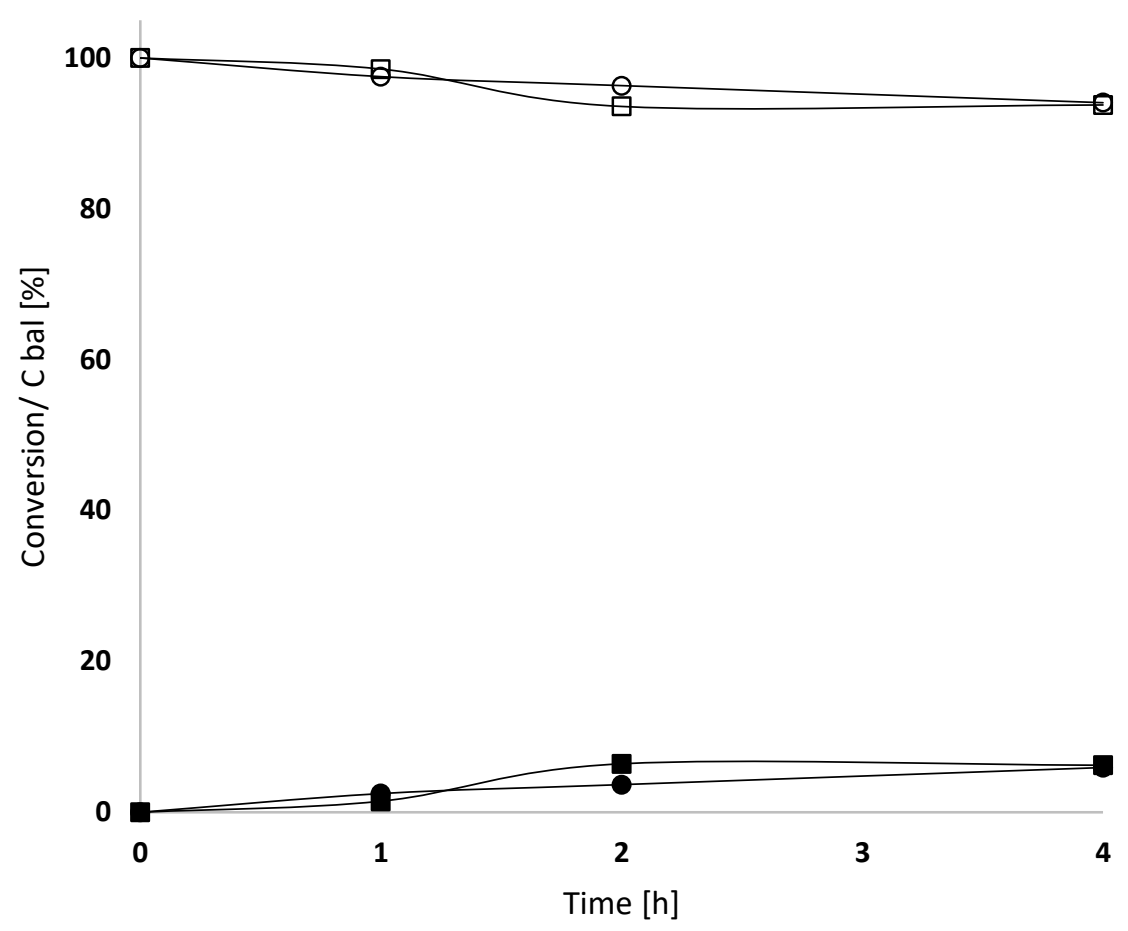

Figure 5 Reaction carried out in the absence of catalyst with the addition of scavengers. Conditions: oxygen pressure, 3 bar; temperature, $120{ }^{\circ} \mathrm{C} ; 0.5 \mathrm{M}$ cinnamyl alcohol in toluene; scavengers: hydroquinone/ diphenylamine, $2 \mathrm{mg}$. Full figures- conversion: empty symbols- carbon balance: reaction with diphenylamine $(\bullet)$, reaction with hydroquinone $(\square)$

After confirmation of the role of radicals in the autoxidation of cinnamyl alcohol, optimisation of the reaction conditions, specifically temperature, was conducted to avoid this autoxidation. A series of $1 \mathrm{~h}$ reactions were carried out at different temperatures under 1 bar $\mathrm{O}_{2}$ pressure (lower than standard 3 bar, to minimise the effect of oxygen radicals) to find the temperature at which the autoxidation starts. The results, presented in Table 1, show that the autoxidation process is active only above $70{ }^{\circ} \mathrm{C}$. As expected, the autoxidation process increases with increase in temperature even under low oxygen pressure.

Table 1: Effect of temperature on the oxidation of cinnamyl alcohol in the absence of catalyst

\begin{tabular}{ccccccc}
\hline \multirow{2}{*}{$\begin{array}{c}\text { Temperature } \\
\text { [C] }\end{array}$} & $\begin{array}{c}\text { Conversion } \\
\text { [\%] }\end{array}$ & C balance & \multicolumn{5}{c}{ Selectivity [\%] } \\
\cline { 4 - 7 } & {$[\%]$} & CinnALD & BenzALD & PP & BenzACID \\
\hline $\mathbf{6 0}$ & - & - & - & - & - & - \\
$\mathbf{7 0}$ & 7 & 95 & 80 & - & 20 & - \\
$\mathbf{8 0}$ & 7 & 95 & 84 & - & 16 & - \\
$\mathbf{9 0}$ & 8 & 99 & 46 & 46 & 8 & - \\
$\mathbf{1 0 0}$ & 8 & 101 & 39 & 47 & 4 & 11 \\
\hline
\end{tabular}

Reaction conditions: oxygen pressure, 1bar; $0.5 \mathrm{M}$ cinnamyl alcohol in toluene. 
We then looked at how the blank reaction compares to the reaction in the presence of catalysts over various temperatures (Table 2). In order to compare the product profiles we carried out the reaction under conditions where the autoxidation is active, i.e. at $80{ }^{\circ} \mathrm{C}$ and above with 3 bar $\mathrm{O}_{2}$. A 4 h oxidation reaction with the use of highly active catalyst at $120{ }^{\circ} \mathrm{C}$ ( 3 bar oxygen) made by sol-immobilisation method showed $87 \%$ conversion and $92 \%$ selectivity to cinnamaldehyde. A 4 hour reaction with the same catalyst, under the same oxygen pressure but at lower temperature $\left(80{ }^{\circ} \mathrm{C}\right)$, gave considerably lower conversion: $30 \%$, however quite high selectivity to cinnamaldehyde: $92 \%$. For the autoxidation reaction, the selectivity towards benzaldehyde $(55-58 \%)$ was always much higher than the selectivity for the desired product cinnamaldehyde (ca. 30\%) for all the temperatures tested $(80,100$ and 120 ${ }^{\circ} \mathrm{C}$ ). When $1 \% \mathrm{AuPd} / \mathrm{TiO}_{2}$ ( $\mathrm{Imp}$ ) catalyst was used, the activity was lower than the autoxidation reaction at all the reaction temperatures tested. For example, at $80{ }^{\circ} \mathrm{C}$, the conversion for autoxidation was $32 \%$, whereas for the catalytic reaction using $1 \% \mathrm{AuPd} / \mathrm{TiO}_{2}$ (Imp) catalyst the conversion was only $10 \%$. This suggests that the impregnation catalyst is somehow inhibiting the reaction. To test if the $\mathrm{TiO}_{2}$ support was acting as a radical scavenger a reaction was carried out at $120{ }^{\circ} \mathrm{C}$ with the addition of bare $\mathrm{TiO}_{2}$, the results are almost identical to the blank reaction. This suggests that the inhibition effect of the impregnation catalyst is related to the metal particles, rather than the support. The difference in benzaldehyde selectivity seems to be an indicator of the extent of the radical autoxidation in this reaction. To try to confirm this we carried out catalysed reactions with the addition of scavengers and the results are shown in figure 6.

Table 2 Effect of temperature on catalysed and uncatalysed reaction of cinnamyl alcohol oxidation under standard conditions after $4 \mathrm{~h}$.

\begin{tabular}{|c|c|c|c|c|c|c|c|c|c|}
\hline \multirow[b]{2}{*}{ Reaction } & \multirow[t]{2}{*}{ Temp } & \multirow[b]{2}{*}{$\begin{array}{r}\text { Conv } \\
{[\%]}\end{array}$} & \multirow{2}{*}{$\begin{array}{c}\mathbf{C} \text { bal } \\
{[\%]}\end{array}$} & \multicolumn{5}{|c|}{ Selectivity [\%] } & \multirow[b]{2}{*}{$\begin{array}{l}\text { Styren } \\
\text { e }\end{array}$} \\
\hline & & & & $\begin{array}{l}\text { CinnAL } \\
\text { D }\end{array}$ & $\begin{array}{l}\text { BenzAL } \\
\text { D }\end{array}$ & PP & MS & $\begin{array}{l}\text { BenzACI } \\
\text { D }\end{array}$ & \\
\hline Blank & 80 & 32 & 89 & 31 & 55 & - & - & 14 & - \\
\hline Imp & 80 & 10 & 103 & 80 & 20 & - & - & - & - \\
\hline SIm & 80 & 33 & 98 & 92 & - & 8 & - & - & \\
\hline Blank & 100 & 37 & 92 & 30 & 52 & - & - & 18 & - \\
\hline $\operatorname{Imp}$ & 100 & 17 & 109 & 66 & 23 & 4 & 2 & 5 & - \\
\hline SIm & 100 & 63 & 95 & 92 & - & 8 & - & - & - \\
\hline Blank & 120 & 54 & 81 & 31 & 58 & 1 & - & 10 & - \\
\hline $\mathrm{TiO}_{2}$ & 120 & 53 & 78 & 34 & 52 & 1 & - & 15 & - \\
\hline $\operatorname{Imp}$ & 120 & 48 & 91 & 60 & 28 & 6 & 2 & 5 & - \\
\hline SIm & 120 & 87 & 100 & 81 & 2 & 10 & 4 & - & 2 \\
\hline
\end{tabular}

Reaction conditions: oxygen pressure, 3bar; 0.5 M cinnamyl alcohol in toluene. 


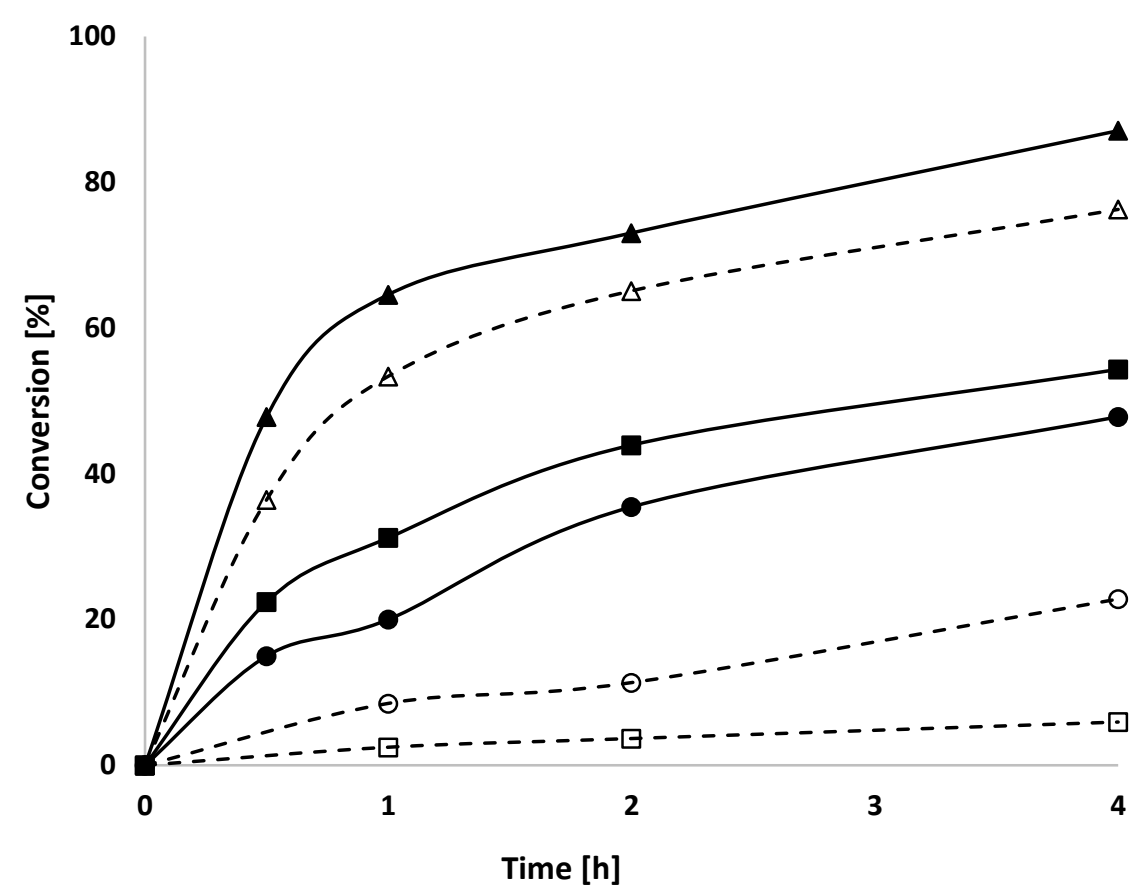

Figure 6 Oxidation of cinnamyl alcohol with the addition of scavenger (hydroquinone) as a function of reaction time. Reaction conditions: $1 \% \mathrm{AuPd} / \mathrm{TiO}_{2}(\mathrm{Imp}), 10 \mathrm{mg}$; oxygen pressure, 3 bar; temperature, $120{ }^{\circ} \mathrm{C} ; 0.5 \mathrm{M}$ cinnamyl alcohol in toluene. Blank (ם); $1 \% \mathrm{AuPd} / \mathrm{TiO}_{2}(\mathrm{SIm})(\mathbf{\Delta})$; $1 \% \mathrm{AuPd} / \mathrm{TiO}_{2}(\operatorname{Imp})(\mathbf{O}) ;$ blank + scavenger $(\square) ; 1 \% \mathrm{AuPd} / \mathrm{TiO}_{2}(\operatorname{Imp})+$ scavenger (O); $1 \% \mathrm{AuPd} / \mathrm{TiO}_{2}(\mathrm{SIm})+\operatorname{scavenger}(\triangle)$.

Radical scavengers slightly decreased conversion of the reaction with the use of a catalyst $1 \% \mathrm{AuPd} / \mathrm{TiO}_{2}(\mathrm{SIm})$, whereas the relative drop for blank and for reaction carried out with the use of catalyst $1 \% \mathrm{AuPd} / \mathrm{TiO}_{2}(\mathrm{Imp})$ was much more significant. Table 3 summarises selectivity to products for the reactions carried out with the addition of scavengers. It can be seen, that scavengers significantly reduced formation of benzaldehyde or even completely stopped the formation in the case of the reaction with the use of catalyst made by the sol-immobilisation method. It has been reported that metal ions (e.g. $\mathrm{Co}^{2+} / \mathrm{Co}^{3+} / \mathrm{Mn}^{2+} / \mathrm{Mn}^{3+}, \mathrm{Fe}^{2+} / \mathrm{Fe}^{3+}, \mathrm{Cu}^{+} / \mathrm{Cu}^{2+}$ ) are able to split hydroperoxides which prevents the processes of autoxidation. ${ }^{27}$ It seems that the reported Au-Pd catalysts have similar properties which are dependent on the size of metal nanoparticles. We consider that the formation of benzaldehyde serves as evidence that an autoxidation process is taking place in the oxidation of cinnamyl alcohol. 
Table 3 Effect of scavengers on catalysed and uncatalyzed reaction of cinnamyl alcohol oxidation under standard conditions after $4 \mathrm{~h}$.

\begin{tabular}{|c|c|c|c|c|c|c|c|c|}
\hline \multirow[b]{2}{*}{ Reaction } & \multirow[b]{2}{*}{$\begin{array}{r}\text { Conv } \\
{[\%]}\end{array}$} & \multirow{2}{*}{$\begin{array}{c}\text { C bal } \\
{[\%]}\end{array}$} & \multicolumn{6}{|c|}{ Selectivity [\%] } \\
\hline & & & $\begin{array}{l}\text { CinnAL } \\
\text { D }\end{array}$ & $\begin{array}{l}\text { BenzAL } \\
\text { D }\end{array}$ & PP & $\begin{array}{l}\mathbf{M} \\
\mathbf{S} \\
\end{array}$ & $\begin{array}{l}\text { BenzACI } \\
\text { D }\end{array}$ & $\begin{array}{l}\text { Styren } \\
\text { e }\end{array}$ \\
\hline Blank & 54 & 81 & 31 & 58 & 1 & - & 10 & - \\
\hline Blank+scavenger & 6 & 94 & 57 & 24 & 19 & - & - & - \\
\hline $\operatorname{Imp}$ & 48 & 91 & 60 & 28 & 6 & 2 & 5 & - \\
\hline Imp+scavenger & 23 & 96 & 83 & 3 & 7 & 7 & - & - \\
\hline SIm & 87 & 100 & 82 & 2 & 10 & 5 & - & 2 \\
\hline SIm+scavenger & 76 & 101 & 84 & - & 12 & 4 & - & - \\
\hline
\end{tabular}

The reported data is in excellent agreement with Ullmann's Encyclopedia of Industrial Chemistry, regarding oxidation reactions. ${ }^{27}$ Only $\mathrm{CO}_{2}$ is stable and all organic species strive to achieve a natural, stable state. ${ }^{27}$ Therefore autoxidation and general aging of organic structures like polymers, paints and also chemicals occurs. The mechanism of autoxidation is not clear and depends on the conditions and on the character of the substrate. Cinnamyl alcohol is prone to autoxidation because of allyl group in its structure. Allylic C-H bonds are roughly $15 \%$ weaker than normal sp ${ }^{3} \mathrm{C}-\mathrm{H}$ bonds. ${ }^{31}$ The initiation factor of this autoxidation is most likely heat ${ }^{27}$ which is in line with the experimental data obtained during these studies. The direct reaction of oxygen with hydrocarbons is spin-forbidden ${ }^{32}$, however at elevated temperatures in the presence of oxygen, radicals (peroxides, hydroperoxides) are formed very easily. ${ }^{27,32}$ A radical mechanism does not require activation energy hence the reaction of hydrocarbons with oxygen is possible. ${ }^{27}$ Weaker allylic $\mathrm{C}-\mathrm{H}$ bonds are easy to break by radicals and radicals are easily attached to the double bond which is the cause of its cleavage. ${ }^{27}$ In view of these facts it may be reasonable to suppose that benzaldehyde is formed from cinnamyl alcohol by a radical pathway, as an effect of autoxidation.

Several studies have suggested that benzaldehyde is formed from cinnamaldehyde and it has been

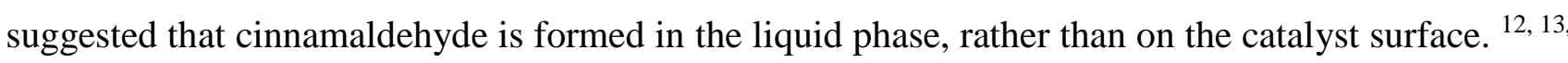
15 Time online studies presented in this work (Figure 2) suggest that all the products were formed simultaneously hence an attempt was made to clarify benzaldehyde formation. To see if benzaldehyde is formed from cinnamaldehyde the oxidation of cinnamaldehyde was carried out under the standard reaction conditions without a catalyst (Figure 7). The number of mols of cinnamaldehyde and benzaldehyde are shown with respect to time. The rate of decrease in the molar amount of cinnamaldehyde closely matches the molar amount of benzaldehyde formed, it does not exactly match the number of mols benzaldehyde produced, suggesting there are side reactions occurring, however 
the relative rates of formation of the product and loss of the reactant suggests that it is a direct transformation.

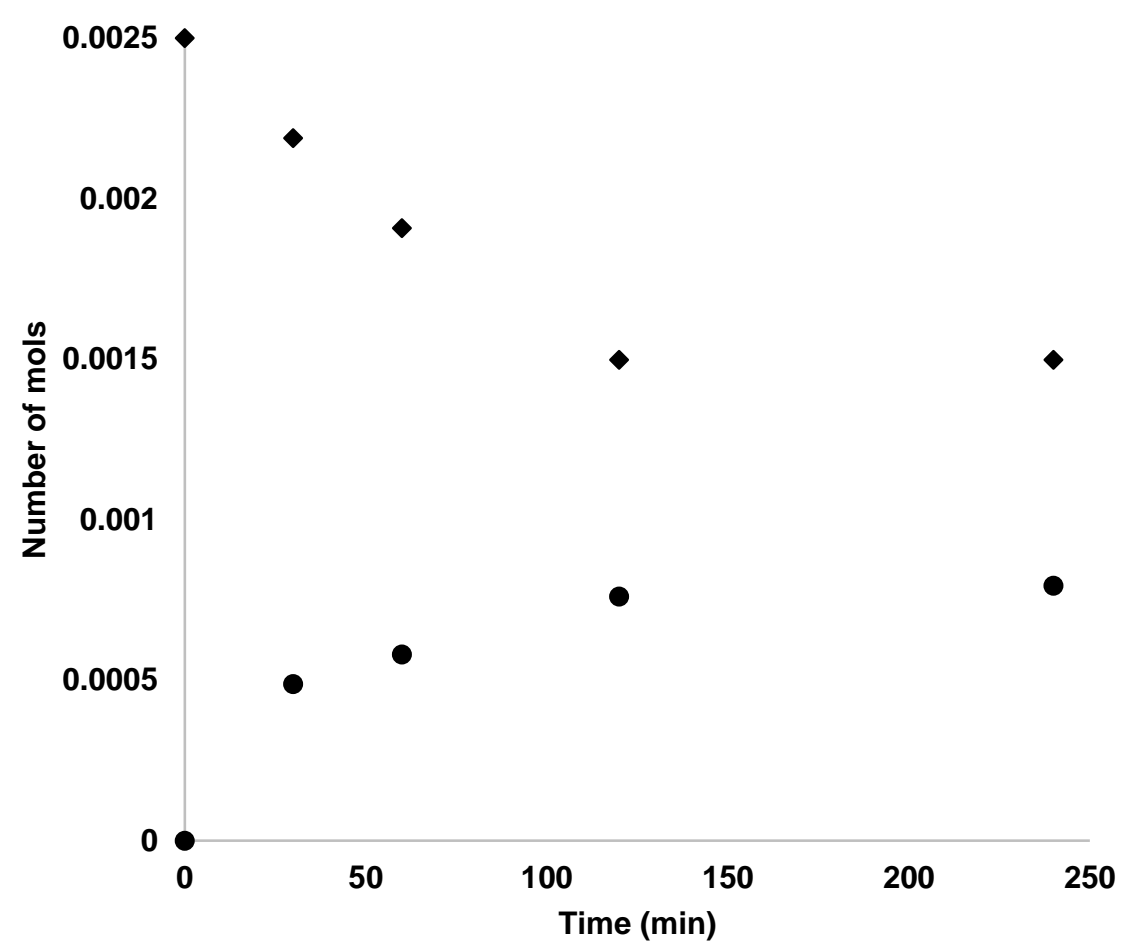

Figure 7: The molar concentration of cinnamaldehyde and benzaldehyde during the oxidation of cinnamaldehyde carried out in the absence of a catalyst as a function of reaction time. Reaction conditions: oxygen pressure, $3 \mathrm{bar}$; temperature, $120^{\circ} \mathrm{C} ; 0.5 \mathrm{M}$ cinnamaldehyde in toluene. Diamonds, CinnALD; circles, BenzALD.

When the number of mols of benzaldehyde formed in relation the number of mols of substrate consumed are compared, under standard reaction conditions there is a clear difference between cinnamyl alcohol and cinnamaldehyde. It is clear from Figure 7 that the autoxidation that occurs in the blank reaction can form benzaldehyde from cinnamaldehyde. Figure 8a shows the number of mols cinnamyl alcohol converted and the number of mols of benzaldehyde formed in the blank reaction and when catalyst are used. We can see that when there is no catalyst or the $1 \% \mathrm{AuPd} / \mathrm{TiO}_{2}(\mathrm{Imp})$ catalyst is present a similar reaction is occurring, which we attribute to autoxidation. However when the $1 \% \mathrm{AuPd} / \mathrm{TiO}_{2}(\mathrm{SIm})$ catalyst is used the conversion of cinnamaldehyde was significantly higher and very little benzaldehyde is formed. This suggests that the reaction in this case is occurring via a different mechanism. When we carry out the same analysis on the reaction starting from cinnamaldehyde (figure $8 \mathrm{~b}$ ) we can see that there is benzaldehyde formed from both the blank reaction 
and the reaction with the $1 \% \mathrm{AuPd} / \mathrm{TiO}_{2}(\operatorname{Imp})$ catalyst. There is also benzaldehyde formed when the $1 \% \mathrm{AuPd} / \mathrm{TiO}_{2}(\mathrm{SIm})$ catalyst is used, this is surprising as we have shown in figure $8 \mathrm{a}$ that the SIm catalyst does not convert cinnamyl alcohol to benzaldehyde. We attribute this to a combination of a competitive adsorption effect and the prevention of the autoxidation pathway, by means of radical quenching, when the sol catalyst is used.
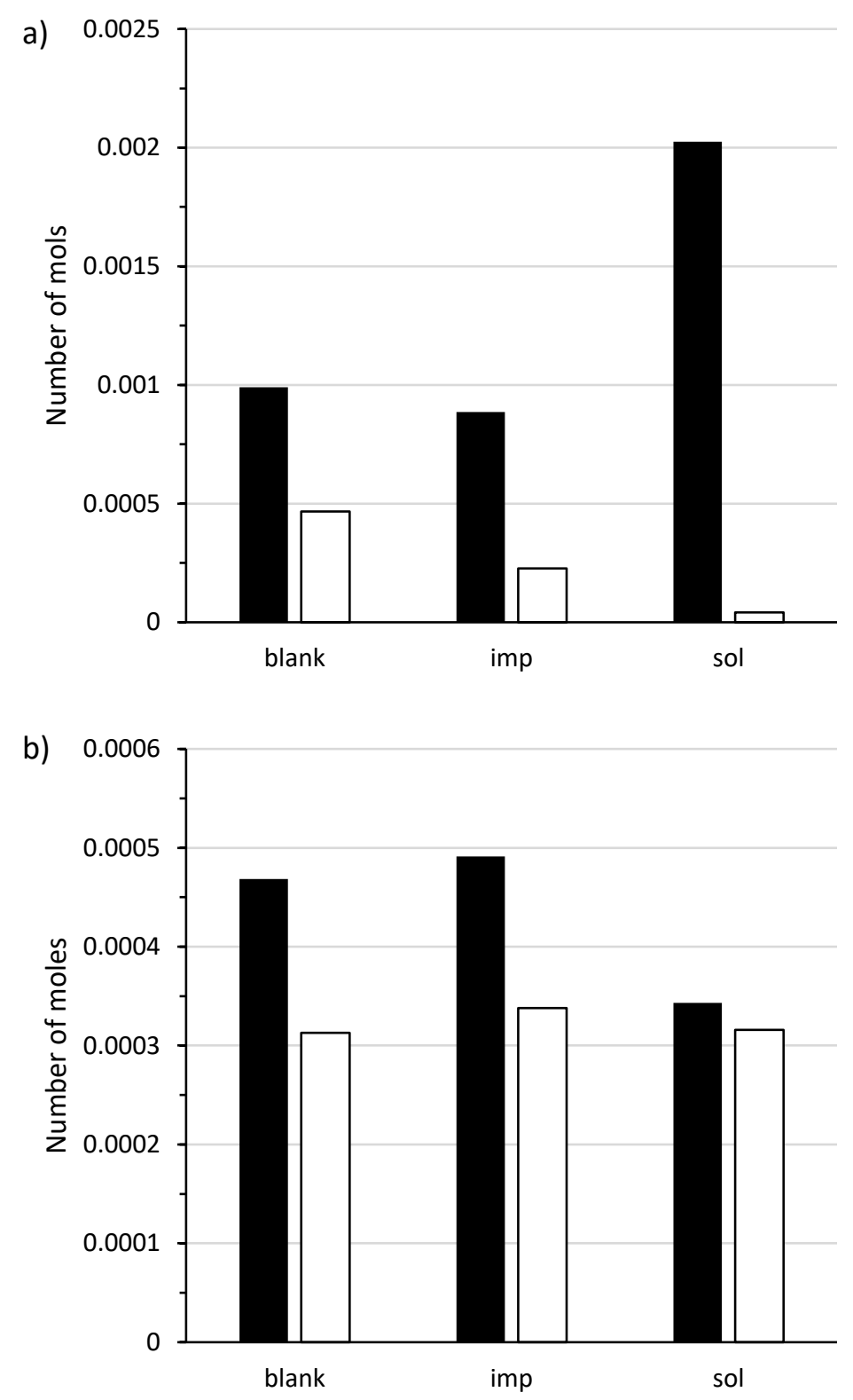

Figure 8 a) the oxidation of cinnamyl alcohol b) the oxidation of cinnamaldehyde. Black boxes number of mol starting material consumed. White boxes - number of mol BenzALD produced. Reaction conditions: time, 2 hours; oxygen pressure, 3 bar; temperature, $120{ }^{\circ} \mathrm{C} ; 0.5 \mathrm{M}$ cinnamaldehyde in toluene. 


\section{Catalyst Characterisation}

\section{SEM}

We have shown that the $\mathrm{TiO}_{2}$ support does not have an influence on the autoxidation process, we therefore attribute the difference in the levels of autoxidation when catalysts are present to the metal nanoparticles. It is clear from the data presented that this effect is different when the different preparation methods are used. We therefore used SEM to investigate the nature of the metal nanoparticles. Figure 9 a shows a $\mathrm{SEM}$ of the $1 \% \mathrm{AuPd} / \mathrm{TiO}_{2}(\mathrm{Imp})$. It is clear on this catalyst that there are extremely large $\sim 100 \mathrm{~nm}$ metal particles, no smaller metal particles were detected, we have previously reported that this preparation method, when used to make a $5 \mathrm{wt} \%$ metal catalyst gives a bi-modal particle distribution with large particles but also small particles $<20 \mathrm{~nm} .{ }^{33}$ In this case, we have used a lower metal loading and there are either no smaller nanoparticles or they are sufficiently small that they are below the detection limit of the SEM. Due to the size of the metal nanoparticles on the impregnation catalyst we were unable to produce a particle size distribution. In contrast small nanoparticles were detectable for the sol-immobilisation prepared catalysts, the nanoparticles were all in the $<10 \mathrm{~nm}$ range, figure $9 \mathrm{~b} \& \mathrm{c}$ shows a representative image and associated particle size count. This is in good agreement with our previous reports. ${ }^{34}$ If there are no, or even very few small nanoparticles in the Imp catalyst, this would explain why it is significantly less active than the SIm catalyst and could explain the difference in the inhibition effect of the autoxidation process. 

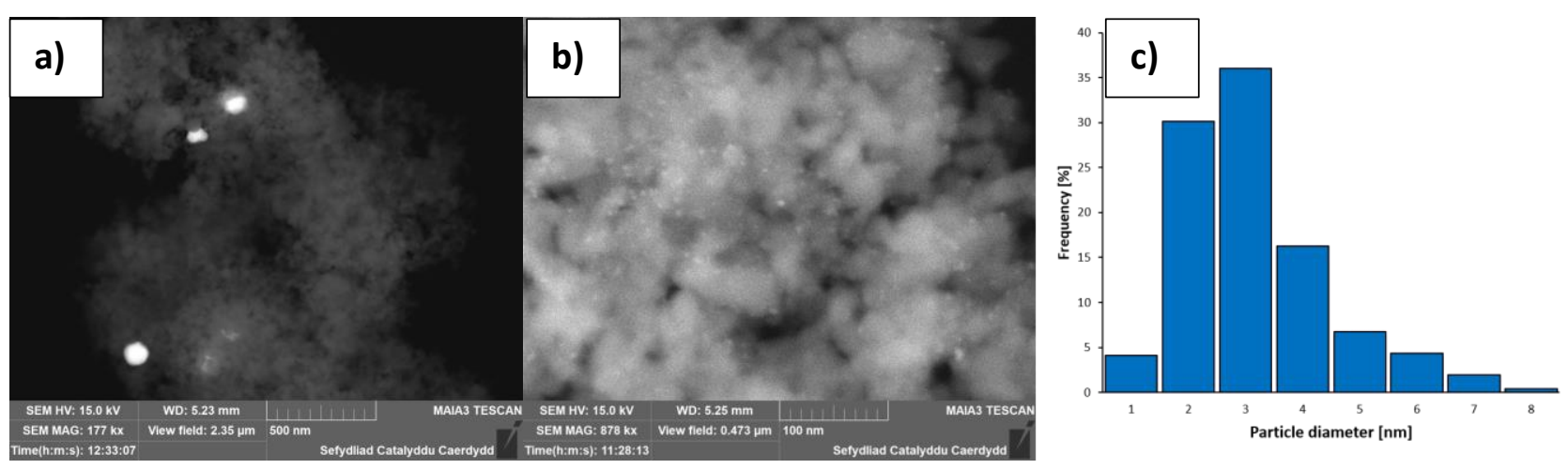

Figure 9 a) BSD-SEM image of the $1 \% \mathrm{AuPd}^{\mathrm{TiO}} \mathrm{Ti}_{2}(\mathrm{Imp})$ catalyst b) BSD-SEM image and associated particle size distribution (c) of the $1 \% \mathrm{AuPd} / \mathrm{TiO}_{2}(\mathrm{Sol})$ catalyst.

\section{XPS}

XPS analysis of the $0.5 \mathrm{Au} 0.5 \mathrm{Pd} / \mathrm{TiO}_{2}(\mathrm{Sol})$ and $(\mathrm{Imp})$ catalysts are in good agreement with the observations from the microscopy studies. Figure 10 shows the $\mathrm{Au}(4 \mathrm{f})$ and $\mathrm{Pd}(3 \mathrm{~d}) / \mathrm{Au}(4 \mathrm{~d})$ core-level spectra for both catalysts and clearly, for the $0.5 \mathrm{Au} 0.5 \mathrm{Pd} / \mathrm{TiO}_{2}(\mathrm{Imp})$ catalyst, the $\mathrm{Au}(4 \mathrm{f})$ signal is weak, which is consistent with poorly dispersed and larger nanoparticles. Whilst the gold is in the metallic state in this catalyst, the $\mathrm{Pd}$ is predominantly present as $\mathrm{Pd}(\mathrm{II})$, which based on the $\mathrm{Pd}(3 \mathrm{~d} 5 / 2)$ binding energy of $336.2 \mathrm{eV}$, we assign as $\mathrm{PdO}$, although the presence of $\mathrm{Pd}-\mathrm{Cl}$ bonds is not whole discounted as $\mathrm{Cl}$ is found at a binding energy of $c a$. $198 \mathrm{eV}$, consistent with metal chlorides. ${ }^{35}$ 
Conversely, the sol prepared catalyst exhibits much more intense Au and Pd signals, consistent with the smaller particle size and hence improved dispersion noted from the SEM. Here the predominant binding energies of $\mathrm{Au}(4 \mathrm{f} 7 / 2)$ at $82.9 \mathrm{eV}$ and $\mathrm{Pd}(3 \mathrm{~d} 5 / 2)$ at $334.3 \mathrm{eV}$ are consistent with their metallic states, ${ }^{35}$ although a trace amount of Pd(II) is found at $335.8 \mathrm{eV}$. The superior efficiency observed by the sol immobilisation catalyst could therefore be due to not only particle size, but also particle morphology, oxidation state of the metals and electronic modification. Certainly we can suggest that the smaller random alloyed sol catalyst is desirable over the larger segregated particles observed in the impregnation catalyst. These effects have previously been studied for benzyl alcohol oxidation over a range of alloyed and segregated AuPd catalysts made by sol immobilisation. ${ }^{36}$ The researchers pointed to the disadvantages of the impregnation method regarding poor control over the particle size distribution and nanoparticle morphology. The sol-immobilisation method was used to prepare $\mathrm{Au}-\mathrm{Pd}$ nanoparticles in three different ways to obtain varying morphologies. Random alloy catalysts were synthesized by the simultaneous addition of gold and palladium precursors before reduction; the Pd-core Au-shell was obtained by reducing the palladium precursor and subsequently adding and reducing the gold precursor; the Pd-shell Au-core was obtained similarly by adding and reducing metal precursors in the reverse order. The researchers concluded that the structure of nanoparticles influences the course of reaction and the behaviour of nanoparticles themselves, especially in terms of activity, thermal stability, sintering and metal-support interaction (wetting behaviours, depending on the support). ${ }^{36}$ It was noted that Pd-shell Au-core catalysts displayed high activity but low selectivity to the desired product. These results suggest that there is a further degree of tailoring available within our sol immobilisation catalysts for the optimisation of cinnamyl alcohol oxidation under autoxidation conditions. 

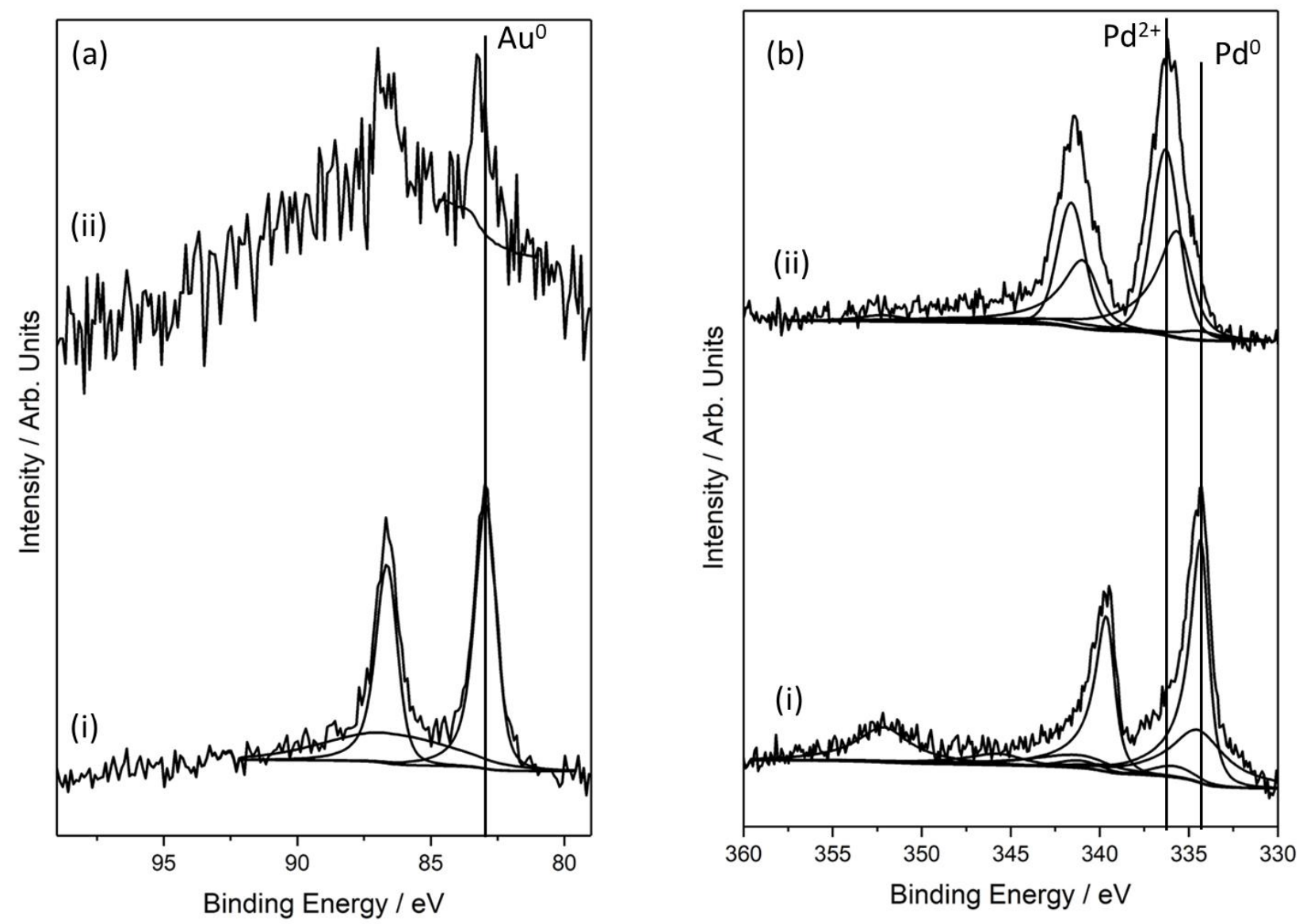

Figure 10 XPS (a) $\mathrm{Au}(4 \mathrm{f})$ and (b) $\mathrm{Pd}(3 \mathrm{~d}) / \mathrm{Au}(4 \mathrm{~d})$ core-level spectra for (i) $0.50 \% \mathrm{Au} 0.50 \% \mathrm{Pd} / \mathrm{TiO}_{2}$ (Sol) and (ii) $0.50 \% \mathrm{Au} 0.50 \% \mathrm{Pd} / \mathrm{TiO}_{2}$ (Imp) catalysts

\section{The role of oxygen on oxidation of cinnamyl alcohol}

The role of $\mathrm{O}_{2}$ in the oxidation of cinnamyl alcohol is still under debate. ${ }^{37,38}$ Baiker et al. conducted in-depth studies on the effect of oxygen on the process. ${ }^{37}$ They observed that dehydrogenation of cinnamyl alcohol over $\mathrm{Pd} / \mathrm{Al}_{2} \mathrm{O}_{3}$ catalysts is independent of the presence of oxygen in the system; however oxygen might clean the catalyst surface and therefore takes a part in the process. ${ }^{37}$ Moreover, cinnamyl alcohol acts as a hydrogen acceptor which is why the selectivity to certain by-products (3phenyl-1-propanol and methylstyrene) increases under inert gas. ${ }^{37}$ Lee et al. suggest that PdO is the active centre and oxygen plays a direct, important role in the catalytic process. ${ }^{38}$

To investigate the role of oxygen in cinnamyl alcohol oxidation, reactions were carried out under $\mathrm{O}_{2}$ and $\mathrm{N}_{2}$ (anaerobic) conditions (Table 4). As expected, there was no autoxidation under anaerobic conditions. However for the catalytic reaction, the activity under anaerobic condition is less than under aerobic condition for $1 \% \mathrm{AuPd} / \mathrm{TiO}_{2}$ (Imp). However, for the anaerobic reaction, there was no benzaldehyde formation and the selectivity for cinnamaldehyde was found to be almost the same for 
both aerobic and anaerobic reactions. Under anaerobic conditions, the selectivities for 3-phenyl-1propanol and methylstyrene, formed by the hydrogenation and hydrogenolysis of cinnamyl alcohol respectively, were higher. However, for the catalytic reaction using $1 \% \mathrm{AuPd} / \mathrm{TiO}_{2}(\mathrm{SIm})$ catalyst, the difference in activities for the aerobic and anaerobic reactions is much smaller compared to the autocatalytic and $1 \% \mathrm{AuPd} / \mathrm{TiO}_{2}(\mathrm{Imp})$ systems. The general trends in the results of the experiments carried out under inert gas are in agreement with the above mentioned literature. ${ }^{12,}{ }^{37}$ It seems likely that hydrogen is abstracted on the catalyst surface and in the next step another molecule of the substrate undergoes hydrogenation/hydrogenolysis. In general the pathway of cinnamaldehyde formation seems to be in good agreement with the mechanism of dehydrogenation/oxidative dehydrogenation reported in the literature. ${ }^{37}$

Table 4 Effect of oxygen and nitrogen on catalysed and uncatalysed reaction of cinnamyl alcohol oxidation under standard conditions after $4 \mathrm{~h}$.

\begin{tabular}{|c|c|c|c|c|c|c|c|c|}
\hline \multirow[b]{2}{*}{ Reaction } & \multirow[b]{2}{*}{$\begin{array}{r}\text { Conv } \\
{[\%]}\end{array}$} & \multirow[b]{2}{*}{$\begin{array}{c}\text { C bal } \\
{[\%]}\end{array}$} & \multicolumn{6}{|c|}{ Selectivity [\%] } \\
\hline & & & $\begin{array}{l}\text { CinnAL } \\
\text { D }\end{array}$ & $\begin{array}{l}\text { BenzAL } \\
\text { D }\end{array}$ & PP & MS & $\begin{array}{l}\text { BenzAC } \\
\text { ID }\end{array}$ & Styrene \\
\hline Blank- $\mathrm{O}_{2}$ & 54 & 81 & 31 & 58 & 1 & - & 10 & - \\
\hline Blank- $\mathrm{N}_{2}$ & - & - & - & - & - & - & - & - \\
\hline Imp-O $\mathrm{O}_{2}$ & 48 & 91 & 60 & 28 & 6 & 2 & 5 & - \\
\hline Imp- $\mathrm{N}_{2}$ & 19 & 103 & 56 & - & 27 & 18 & - & - \\
\hline SIm-O ${ }_{2}$ & 87 & 100 & 82 & 2 & 10 & 5 & - & 2 \\
\hline SIm-N 2 & 86 & 100 & 58 & - & 13 & 30 & - & - \\
\hline
\end{tabular}

ESI Figure 1 illustrates the influence of oxygen pressure on the conversion for the reaction carried out in the presence of the catalyst (prepared by impregnation method) and absence of a catalyst. The higher the pressure the higher the conversion. ESI Figure 2 plots selectivity to cinnamaldehyde and benzaldehyde in terms of oxygen pressure. The increase in pressure resulted in increased selectivity to benzaldehyde while a decrease in selectivity to cinnamaldehyde was observed. This is consistent with observations that are reported by Rossi et al. ${ }^{15}$ Pressure did not affect the activity of the catalyst made by sol-immobilisation method. Conversion and selectivity were steady in the range of tested oxygen pressure (1-3 bar). It is also further confirmation of the hypothesis that the formation of benzaldehyde is as the result of the autoxidation of cinnamyl alcohol in the presence of oxygen. 


\section{Effect of water}

It has previously been shown that in the oxidation of alcohols by permanganate the presence of moisture is beneficial in terms of a higher yield to the desired product. ${ }^{39}$ Kozhevnikov et al. proved in their work that addition of water can significantly improve the activity of the Pd-M oxide catalysts in the transformation of alcohols. ${ }^{40}$ Prati et al. used water instead of toluene in the oxidation of cinnamyl alcohol and obtained higher yield to cinnamaldehyde. ${ }^{11}$ We investigated the effect of the addition of a small amount of water to our oxidation system and the results are shown in table 5 .

It can be seen that the conversion of the blank reaction decreased significantly with the addition of water. Generally, the solubility of oxygen is lower in water than in organic solvents. ${ }^{41,42}$ Hypothetically, the addition of water can reduce the solubility or available amount of oxygen in the reaction mixture which could explain the decrease in activity. The selectivity to cinnamyl aldehyde was significantly increased for both the blank reaction and the reaction with catalysts. Hermans and Neuenschwander have extensively studied the autoxidation of hydrocarbons where water is formed as a by-product. They suggest that the water is an effective shield between radicals and might be hydrogen-bonded to the alkoxyl radical. ${ }^{25}$ In this manner water can prevent the interaction of a radical with a substrate or other compounds in the system. We propose that the water is quenching or preventing the radical mechanism in this case. This is supported by the selectivity to cinnamaldehyde which is higher for both the blank reaction and the impregnation catalyst, the reactions where the autoxidation is dominant.

The oxidation carried out with sol catalyst takes place on the catalytic pathway. It can be seen from Table 5 that water increased the activity of catalyst prepared by sol-immobilisation method, however the selectivity to cinnamaldehyde slightly decreased in favour of PP. This result is in line with the findings reported by Prati, namely that water acts as a weak base leading to easier abstraction of hydrogen, which is transferred to another molecule of the alcohol causing its hydrogenation (hence the higher selectivity to PP). The small amounts of benzaldehyde have been presumably been formed from cinnamaldehyde as the radical pathway is switched off. Overall the behaviour of the reaction under the various conditions supports our previous results that suggest that the autoxidation reaction is a radical reaction that does not occur when the sol immobilisation catalyst is used.

Table 5 Effect of the small addition of water $(2 \mathrm{ml})$ on catalysed and uncatalyzed reaction of cinnamyl alcohol oxidation under standard conditions after $4 \mathrm{~h}$.

\begin{tabular}{|c|c|c|c|c|c|c|c|c|}
\hline \multirow[b]{2}{*}{ Reaction } & \multirow[b]{2}{*}{$\begin{array}{c}\text { Conversion } \\
{[\%]}\end{array}$} & \multirow[b]{2}{*}{$\begin{array}{c}\text { C bal } \\
{[\%]}\end{array}$} & \multicolumn{6}{|c|}{ Selectivity [\%] } \\
\hline & & & $\begin{array}{l}\text { CinnAL } \\
\text { D }\end{array}$ & $\begin{array}{l}\text { BenzAL } \\
\text { D }\end{array}$ & PP & $\begin{array}{l}\text { M } \\
\text { S }\end{array}$ & $\begin{array}{l}\text { BenzACI } \\
\text { D }\end{array}$ & $\begin{array}{l}\text { Styren } \\
\text { e }\end{array}$ \\
\hline Blank & 54 & 81 & 31 & 59 & 1 & - & 10 & - \\
\hline
\end{tabular}




\begin{tabular}{lcccccccc} 
Blank+water & 17 & 95 & 41 & 54 & 5 & - & - & - \\
Imp & 47 & 91 & 60 & 28 & 6 & 2 & 5 & - \\
Imp+water & 36 & 100 & 87 & 10 & 3 & - & - & - \\
SIm & 87 & 100 & 82 & 2 & 10 & 5 & - & 2 \\
SIm+water & 100 & 100 & 72 & 7 & 19 & 2 & - & - \\
\hline
\end{tabular}

\section{Conclusions}

In this work we have examined the oxidation of cinnamyl alcohol in detail. It was found that the autoxidation reaction is prevalent in the blank reaction and when low activity catalysts are used. This autoxidation pathway leads to the formation of large amounts of benzaldehyde, an undesirable product. Furthermore, the presence of benzaldehyde in the reaction at low conversion is an indicator that an autoxidation process is taking place.

Small particles (3-5 nm) obtained by sol-immobilisation method are able to split peroxides/hydroperoxides caused by the autoxidation process thus enabling high selectivity to cinnamaldehyde. Larger particles (around $20 \mathrm{~nm}$ ) achieved via impregnation method are less active in the oxidation of cinnamyl alcohol and the product distribution suggests that the autoxidation and catalytic mechanisms take place simultaneously. By careful choice of catalyst we can prevent the autoxidation process, which negates the need to try to manipulate the reaction conditions to maximise the yield, by using the sol-immobilisation catalyst we operate the reaction at higher temperatures and pressures of oxygen which leads to higher activity and greater yields of the desired product cinnamaldehyde. We suggest that these results could have further implications for similar selective oxidation reactions under conditions where undesirable autoxidation is commonly the dominant process.

\section{Acknowledgements}

We would like to thanks the Cardiff University electron microscopy facility for the scanning electron microscopy (SEM).

\section{References}

1. P. J. Miedziak, Q. He, J. K. Edwards, S. H. Taylor, D. W. Knight, B. Tarbit, C. J. Kiely and G. J. Hutchings, Catalysis Today, 2011, 163, 47-54.

2. G. J. Hutchings, Catalysis Today, 2005, 100, 55-61. 
3. A. Abad, C. Almela, A. Corma and H. Garcia, Chemical Communications, 2006, DOI: 10.1039/B606257A, 3178-3180.

4. S. Meenakshisundaram, E. Nowicka, P. J. Miedziak, G. L. Brett, R. L. Jenkins, N. Dimitratos, S. H. Taylor, D. W. Knight, D. Bethell and G. J. Hutchings, Faraday Discussions, 2010, 145, 341-356.

5. E. Cao, M. Sankar, E. Nowicka, Q. He, M. Morad, P. J. Miedziak, S. H. Taylor, D. W. Knight, D. Bethell, C. J. Kiely, A. Gavriilidis and G. J. Hutchings, Catalysis Today, 2013, 203, 146-152.

6. N. Al-Rifai, F. Galvanin, M. Morad, E. Cao, S. Cattaneo, M. Sankar, V. Dua, G. Hutchings and A. Gavriilidis, Chemical Engineering Science, 2016, 149, 129-142.

7. M. Jiménez-Salcedo and M. T. Tena, Journal of Chromatography A, 2017, 1487, 14-21.

8. Y. E. Na, S.-I. Kim, H.-S. Bang, B.-S. Kim and Y.-J. Ahn, Veterinary Parasitology, 2011, 178, 324-329.

9. C. Villegas, A. Torres, M. Rios, A. Rojas, J. Romero, C. L. de Dicastillo, X. Valenzuela, M. J. Galotto and A. Guarda, Food Research International, 2017, 99, 650-659.

10. A. R. Williams, T. V. A. Hansen, L. Krych, H. F. B. Ahmad, D. S. Nielsen, K. Skovgaard and S. M. Thamsborg, Veterinary Immunology and Immunopathology, 2017, 189, 43-52.

11. N. Dimitratos, A. Villa, D. Wang, F. Porta, D. Su and L. Prati, Journal of Catalysis, 2006, 244, 113-121.

12. J.-D. Grunwaldt, C. Keresszegi, T. Mallat and A. Baiker, Journal of Catalysis, 2003, 213, 291-295.

13. G. Wu, G. L. Brett, E. Cao, A. Constantinou, P. Ellis, S. Kuhn, G. J. Hutchings, D. Bethell and A. Gavriilidis, Catalysis Science \& Technology, 2016, 6, 4749-4758.

14. M. Caravati, D. M. Meier, J.-D. Grunwaldt and A. Baiker, Journal of Catalysis, 2006, 240, 126-136.

15. J. C. S. Costa, P. Corio and L. M. Rossi, Nanoscale, 2015, 7, 8536-8543.

16. I. B. Niklasson, T. Delaine, M. N. Islam, R. Karlsson, K. Luthman and A.-T. Karlberg, Contact Dermatitis, 2013, 68, 129-138.

17. M. Conte, X. Liu, D. M. Murphy, K. Whiston and G. J. Hutchings, Physical Chemistry Chemical Physics, 2012, 14, 16279-16285.

18. I. Hermans, P. A. Jacobs and J. Peeters, Chemistry - A European Journal, 2006, 12, 4229-4240.

19. B. Saha, N. Koshino and J. H. Espenson, The Journal of Physical Chemistry A, 2004, 108, 425-431.

20. J.-A. Becerra, L.-M. González and A.-L. Villa, Journal of Molecular Catalysis A: Chemical, 2016, 423, $12-21$.

21. Y. Cao, Y. Li, H. Yu, F. Peng and H. Wang, Catalysis Science \& Technology, 2015, 5, 3935-3944.

22. A. Bhattacharya, Chemical Engineering Journal, 2008, 137, 308-319.

23. X. Liu, Y. Ryabenkova and M. Conte, Physical Chemistry Chemical Physics, 2015, 17, 715-731.

24. I. Hermans, P. A. Jacobs and J. Peeters, Journal of Molecular Catalysis A: Chemical, 2006, 251, 221228.

25. U. Neuenschwander and I. Hermans, Journal of Catalysis, 2012, 287, 1-4.

26. N. Dimitratos, J. A. Lopez-Sanchez, D. Morgan, A. Carley, L. Prati and G. J. Hutchings, Catalysis Today, 2007, 122, 317-324.

27. G. Franz and R. A. Sheldon, in Ullmann's Encyclopedia of Industrial Chemistry, Wiley-VCH Verlag GmbH \& Co. KGaA, 2000, DOI: 10.1002/14356007.a18_261.

28. S. Fujisawa, M. Ishihara and Y. Kadoma, Antioxidant Activity of Diphenylamine-Related Compounds as Scavengers of Carbon Radicals, 2005.

29. J. A. Muccitelli, Google Patents, 1984.

30. V. Thavasi, R. P. A. Bettens and L. P. Leong, The Journal of Physical Chemistry A, 2009, 113, 30683077.

31. P. Deshlahra and E. Iglesia, The Journal of Physical Chemistry C, 2016, 120, 16741-16760.

32. U. Neuenschwander, N. Turrà, C. Aellig, P. Mania and I. Hermans, CHIMIA International Journal for Chemistry, 2010, 64, 225-230.

33. J. K. Edwards, A. F. Carley, A. A. Herzing, C. J. Kiely and G. J. Hutchings, Faraday Discussions, 2008, 138, 225-239.

34. J. A. Lopez-Sanchez, N. Dimitratos, P. Miedziak, E. Ntainjua, J. K. Edwards, D. Morgan, A. F. Carley, R. Tiruvalam, C. J. Kiely and G. J. Hutchings, Physical Chemistry Chemical Physics, 2008, 10, 1921-1930. 
35. M. Sankar, Q. He, M. Morad, J. Pritchard, S. J. Freakley, J. K. Edwards, S. H. Taylor, D. J. Morgan, A. F. Carley, D. W. Knight, C. J. Kiely and G. J. Hutchings, ACS Nano, 2012, 6, 6600-6613.

36. R. C. Tiruvalam, J. C. Pritchard, N. Dimitratos, J. A. Lopez-Sanchez, J. K. Edwards, A. F. Carley, G. J. Hutchings and C. J. Kiely, Faraday Discussions, 2011, 152, 63-86.

37. C. Keresszegi, T. Bürgi, T. Mallat and A. Baiker, Journal of Catalysis, 2002, 211, 244-251.

38. C. M. A. Parlett, L. J. Durndell, K. Wilson, D. W. Bruce, N. S. Hondow and A. F. Lee, Catalysis Communications, 2014, 44, 40-45.

39. W. S. Trahanovsky and Editor, Organic Chemistry, Vol. 5: Oxidation in Organic Chemistry, Pt. D, Academic Press, 1982.

40. T. L. Stuchinskaya and I. V. Kozhevnikov, Catalysis Communications, 2003, 4, 417-422.

41. D. Tromans, Hydrometallurgy, 1998, 48, 327-342.

42. A. Li, S. Tang, P. Tan, C. Liu and B. Liang, Journal of Chemical \& Engineering Data, 2007, 52, 23392344. 